unattended with much sickness. During this pregnancy, however, the sickness was troublesome from the first, and it increased as the pregnancy advanced, the skin assuming a most unhealthy, sallow appearance, as if the liver was not acting. She lost flesh rapidly, but was not confined to her bed until the end of the sixth month, when she had a most severe attack of vomiting, large quantities of bile being romited up. For about a fortnight hardly anything seemed to be retained, and she became so prostrated that $I$ began to think it would be necessary to induce labour. However, at the end of a fortnight she improved a little, and some water gruel and essence of meat were retained. In another week she was able to sit up a little each day, but still the vomiting never ceased entirely, and until her confinement not a day passed without severe attacks of it. All the usual remedies were tried without much effect. Bismuth seemed to do the most good. She was now able to sit up each day, and was downstairs the day before her confinement. A fortnight previously, however, she felt her legs cold, and found she was losing the use of them; she had to be assisted up and down the stairs. She had no pain-only the feeling of coldness in the legs; she tried to obtain warmth in them by sitting before the fire, but in vain. Prior to this pregnancy she was a little inclined to stoutness, and I think she lost at least $80 \mathrm{lb}$. in weight. Labour was quite natural, lasting about five hours. The romiting ceased the day after, and she began to take nourishment. She had no rise of temperature, the lochia were normal, and it was thought she was doing well. However, after the fourth day she complained of her legs feeling numb, and a few days afterwards of severe pains in them and of "pins-andneedles" in the hands, a burning sensation in the palms, and pains up the arms. She could move her legs slightly in bed, and the wrists did not drop until the twelfth day after confinement. On the thirteenth day we got her out of bed, and it was then that I saw the extensive nature of the disease. Dr. Dreschfeld saw her with me on this date, when we found she had almost lost the entire use of both arms and legs. She was unable to bear the slightest weight on her legs, and had difficulty in crossing one over the other. The patellar and other reflexes were absent; both feet were extended and the toes flexed; the hands were dropped, the wrist and fingers were flexed, and she had no power to extend them. She had difficulty in raising herself in bed, and complained of a peculiar numb feeling around the lower part of the abdomen and epigastric region. The breathing fortunately was unaffected. There was pain on pressure over the main nerve trunks in both arms and legs. The cutaneous sensibility varied in different placesincreased in some parts, diminished in others. We gave her liq. strychniæ, and employed massage, and in about a week she began to improve. The improvement has been slow but continuous, and at the present time the arms, forearms, thighs, and trunk are almost well, but the hands, legs, and feet are not. She cannot bear any weight on the feet as yet, although she can flex them and move them about more freely, and power is certainly returning gradually.

Remarks. - Of course peripheral neuritis may come on during any wasting disease, and very rarely after a confinement ; but I am not aware of any case having been described which has been due to excessive vomiting during pregnancy. The ouestion is, whether, should the symptoms show themselves during an excessively sick pregnancy, it would not be a sufficient reason for inducing premature labour. In this case the early symptoms were extreme coldness of the lower limbs from the hips downwards, with partial loss of power, followed by a feeling of numbness.

Manchester.

\section{CASE OF ABSCESS OF LIVER; OPERATION; RECOVERY.}

Bx Walter Falla, M.R.C.S., L.R.C.P., STRGEON TO THE JERSEY GENERAL HOSPITAL.

ON Nov. Plst last I was called to see L. S- - aged twenty-six, of temperate habits. He had been ill about a fortnight, and complained of great pain in the epigastrium, with occasional rigors, and a temperature of $103^{\circ}$. On examining the abdomen, $I$ found a distinet fulness, dull on percussion, over the left lobe of the liver, which was very tender on pressure. The pain was relieved by hot fomentations and opiates for a few days, but the swelliing gradually increased, the temperature varying from $102^{\circ}$ to $105^{\circ}$, while he was rapidly losing appetite and flesh. On Nov. 28 th, Dr. Bentlif kindly saw the case in consultation with me, and agreed that the diagnosis was abscess of the left lobe of the liver. The following day, after first confirming our diagnosis by making an exploratory puncture with a hypodermic syringe, we decided to aspirate, and withdrew four ounces of deep-seated pus. The relief which followed was only very temporary; the swelling in the epigastrium soon reappeared, and increased so rapidly that on Dec. 4th it was larger than ever. We decided again to operate at once. Dr. Bentlif administered chloroform, while I made a free incision, letting out about six ounces of pus. I inserted a drainage-tube, and dressed the wound with iodoform and carbolised wool ; the temperature very soon became normal, and he made a speedy recovery. The wound was dressed daily, the abscess cavity washed out with a warm and weak solution of carbolic acid, and the drainage-tube removed seven days after the operation. On Dec. 16 th the wound had quite healed, and the patient was able to get up, feeling almost quite well.

Remarks. - This case is interesting, not only as occurring in a person who has never lived in the tropics, but also on account of his youth and temperate habits, and without any apparent cause to account for it. I have seen several cases of abscess of the liver in India. With regard to treatment, my experience has been that aspirating is very rarely sufficient to effect a cure ; in the great majority of cases, it is either necessary to make a free incision or to puncture with a large trocar and cannula, so as to allow free drainage.

st. Heliers, Jersey.

\section{g a}

\section{OP}

\section{HOSPITAL PRACTICE, BRITISH AND FOREIGN.}

Nulla autem est alia pro certo noscendi via, nisi quamplurimas et morborum et dissectionum historias, tum aliorum tum proprias collectas habere, et inter se comparare.-MORGAGNI De Sed. et Caus. Hiort, lib. iv. Procemium.

\section{GUY'S HOSPITAL.}

VAGINAL LITHOTOMY IN A PATIENT SIX MONTHS AND A

HALF PREGNANT; IMMEDIATE SUTURE OF WOUND;

RECOVERY ; NORMAL DELIVERY AT FULL TIME ; REMARKS.

(Under the care of Mr. JACOBSON.)

THE operation for removal of a stone from the female bladder may be performed by cystotomy in four different ways. 1. By the direct method, a transverse incision between the urethra and the pubes, not now used. 2. Division of the urethra and neck of the bladder, either immediately or after a lateral incision. 3. Incision above the pubes. 4. Vesico-vaginal incision as practised by $\mathrm{Mr}$. Jacobson, who gives reasons for the employment of this method in his remarls on the case. ${ }^{1}$ Hugenberger has collected a series of twenty-three cases of stone in the bladder during pregnancy, from which it appears the operation for their removal has been practised at different, periods of pregnancy, but although the stone has been removed successfully, death has not unfrequently occurred. Should a calculus only be discovered during parturition, and its size or position in front of the advancing head prevent its displacement to a part where it is less likely to cause damage, it may be necessary to perform the operation of vaginal cystotomy. We have frequently drawn attention to the operation of lithotomy in the fenale in the columns of THE LANCET. ${ }^{2}$ The following account is taken from the notes of the case by Mr. J. H. Bryant.

A. L- , aged twenty-seven, was sent to the hospital by Dr. Montagu Day, of Harlow, Essex, on Dec, 7th, 1888. She had lived in that neighbourhood all her life. For about three years she had had "bladder trouble"-viz., hypogastric pain, cystitis, very frequent micturition day and night, with

See Gant, Science and Practice of Surgery, vol. ii., p. 982.

2 1838-9, vol. i., p. 58 ; 1862 , vol. ii., p. $478 ; 1863$, vol. i., p. $34 ; 1870$, vol. ii., p. 853 ; 1885 , vol. ii., p. 847 . 